\title{
A Comparative Study on Stabilization of Natural Medium Expansive Soil using Cement and Fly ash
}

\author{
Md. Jan - E - Alam ${ }^{1}$, Saddam Hossain ${ }^{2}$, Prince Reza ${ }^{2}$, Rafiqul Islam ${ }^{3}$ \\ ${ }_{1,2}$ (Department of Civil Engineering, European University of Bangladesh, Bangladesh) \\ ${ }^{3}$ (Department of Civil Engineering, Dhaka International University, Bangladesh)
}

\begin{abstract}
Soil is most unpredictable materials for civil engineering construction. The objective of this paper is to improve natural soil as a construction material using cement and fly ash. In this paper, ordinary portland cement and fly ash were evaluated as potential stabilizers in enhancing mechanical properties of natural soil. The soil collected from the selected side of Barisal region used in this study for soil stabilization by mixing various percentage of cement content 5\%,10\% and 15\% with respect to dry soil. The Unconfined Compression Strength (UCS) and California Bearing Ratio (CBR) test performed on curing period of 7 days, 14 days, 21 days and 28 days. Improvement of UCS and CBR values observed with the rapid increment in the percentages of cement and fly ash content. During treatments, Cement was the most effective treatment of this soil, where the soil mechanical property enhancements considered as significant. In addition, fly ash mixed soil strength development also considerable because of its cost-effectiveness. It also found that the strength and CBR values improve with the increasing of curing period. The suitability of the stabilization technique have been studied with respect to the cost and strength.
\end{abstract}

Keywords: CBR values, Cement, Fly Ash, Natural Soil, Strength Development

\section{Introduction}

The Rapid urbanization followed by population growth requires varies types of civil engineering infrastructure and facility service. Because of scarcity of suitable lands, it has become difficult to select and appropriate location for infrastructure. At present, for various types of construction engineer are forced to lay foundation on soft ground. The negative effect of soft ground like low strength, stability, high settlement, differential settlement or time-settlement sometimes no choice other than rejection-replacement, excavation and dumping as a waste. Because of the environmental consideration dumping of rejected soft soil also, increase cost effective on any construction project. Growing environmental awareness about contaminated soil because of human and geological activities has also become a burning issue. Ground improvement by treating soft-soil or contaminated soil with varies types of binders is an attractive alternative and often economical compared to other ground improvement method. Addition of binders alters the engineering properties of the existing soil to create a new site material, which is capable to meet certain material requirements.

To improve the bearing capacity of foundation, subgrade etc. soil stabilization by mixing chemical admixtures (e.g. cement, lime, fly-ash etc.) was studied by many researchers (e.g. Bjerrum and Edie, 1956[1]; Herrin and Mitchell, 1961[2];). They observed in their research that the supporting power of the soil could be significantly increased by stabilizing the loose or soft soil. Soil stabilization is the technique for improving the natural sub soil and making stable site for construction. This technique can be done by the use of controlled compaction, proportioning and the addition of suitable different types of admixtures. There are various industries in all over the world which Generates waste by products every year such as fly ash, blast furnace slag, cement kiln dust, and limestone dust. Therefore, its safe disposal or beneficial utilization is necessary because it produces the environment pollution problem. Using industrial by-products such as fly ash, blast furnace slag, cement kiln dust, and limestone dust, among many others, as additives to civil engineering construction materials helps arrest their hazardous effects on the environment and reduce construction costs (Phanikumar and Sharma 2004[3]; Malhotra and Mehta 1996[4]; Cokca 2001[5]).

Cement hydration requires only water and form cementation products within a short time. For this reason cement or cement, dominating binder can provide early strength characteristic and generally successful for any type of clay. On the other hand binder depends on pozzolanic reaction provide strength slowly and depends either on soil or on the characteristics of other additives (for an example fly ash/ silica lime). Latent hydraulic material, slag contains lime but require activation by $\mathrm{Ca}(\mathrm{OH}) 2$, before it can be react with water. The reaction products of lime and Portland cement contain $\mathrm{Ca}(\mathrm{OH}) 2$, making these product excellent activation for slag. After the slag is activated, the reaction takes places largely spontaneously with its own lime content.

Ahnberg and Johansson (2005) [6] presented a rough outline of the principal chemical reaction and reaction products formed by different types of binder in a soil (Figure 1). However, these binders have 
somewhat different reaction and require different conditions in order to perform, but their reaction products are closely similar.

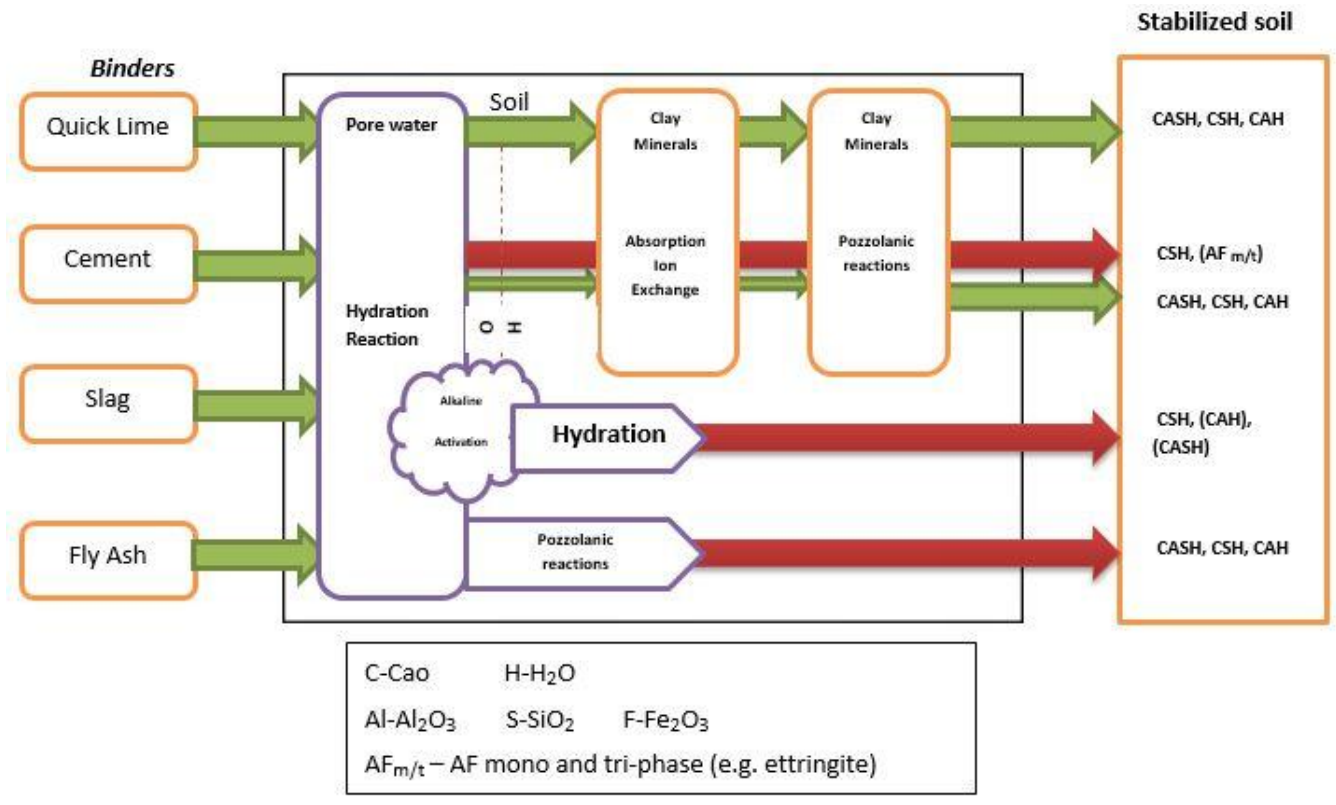

Figure 1: A rough outline of the principal chemical reaction and reaction product formed different types of binder in a soil (Ahnberg and Johansson, 2005) [6].

\subsection{Natural Soil}

\section{Materials}

Natural soil samples are taken from Barisal region from depth of $10 \mathrm{ft}$ to $18 \mathrm{ft}$ from ground level. The soil was air dried and pulverized manually. Natural soil has the swelling and shrinkage properties in the present of moisture. This natural soil is grey and black in color and small portion of soil is red color. All through the treatment process, the soil sample was oven dried at $105^{\circ}$ to $115^{\circ} \mathrm{C}$. Soil scientist describes the soil type by how much sand, silt and clay are Present, and this called texture. It is possible to change the texture by adding different things. Soil Texture classes are followed Sandy - soils containing more than 70\% sand; Silt - soils containing more than $80 \%$ silt; Clay - soils containing more than $40 \%$ clay. Basic properties of the natural untreated soil used in experiment work are presented in table 1.

Table 1: Natural Soil Properties

\begin{tabular}{|c|c|c|}
\hline Sl. No. & Type & Values \\
\hline 1. & Gravel & $4 \%$ \\
\hline 2 & Sand & $62 \%$ \\
\hline 3. & Silt & $12 \%$ \\
\hline 4. & Clay & $24 \%$ \\
\hline 5. & Liquid Limit & $35.8 \%$ \\
\hline 6. & Plastic Limit & $19.11 \%$ \\
\hline 7. & Plasticity Index & $16.69 \%$ \\
\hline 8. & Optimum Moisture Content & $27.8 \%$ \\
\hline 9. & Maximum Dry Density & $1140 \mathrm{~kg} / \mathrm{m}^{3}$ \\
\hline 10. & Unconfined compression strength (UCS) & $134.26 \mathrm{kPa}$ \\
\hline 11. & California Bearing Ratio (CBR) & 2.82 \\
\hline
\end{tabular}

\subsection{Cement}

A Portland cement particle is a heterogeneous substance, containing minute tricalcium silicate $\left(\mathrm{C}_{3} \mathrm{~S}\right)$, dicalcium silicate $\left(\mathrm{C}_{2} \mathrm{~S}\right)$, tricalcium Aluminate $\left(\mathrm{C}_{3} \mathrm{~A}\right)$ and solid solution described as tetra calcium aluminoferrite $\left(\mathrm{C}_{4} \mathrm{AF}\right)$ (Lea, 1956). When the pore water of the soil encounters with cement, hydration of the cement occurs rapidly and major hydration produce hydrated calcium silicates $(\mathrm{C}-\mathrm{S}-\mathrm{H})$ and hydrated lime $\left(\mathrm{Ca}(\mathrm{OH})_{2}\right)$. Calcium silicate hydrate is the main product of the hydration of Portland cement and is primarily responsible for the strength in cement-based materials. The Scan Cement is manufactured by Heidelberg Cement Group was used in this study. The properties of cement are shown in table 2 . 
Table 2: Properties of Cement

\begin{tabular}{|c|c|c|}
\hline Sl. No. & Type & Values \\
\hline 1. & Normal Consistency & $36 \%$ \\
\hline 2. & Fineness of Cement & $7 \%$ \\
\hline 3. & Specific Gravity & 3.15 \\
\hline 4. & Initial and final Setting Time & 45 min and $625 \mathrm{~min}$ \\
\hline
\end{tabular}

\subsection{Fly Ash}

Fly ash is one of the most plentiful and versatile by-products generated in large quantities from burning coal at electric power plants; fly ash is usually recycled as an engineering material to take advantage of its pozzolanic characteristics. It offers economical alternatives for a wide range of soil stabilization applications. The potential for using fly ash in soil stabilization has increased significantly in Bangladesh due to increased availability and the introduction of new environmental regulations that encourage the use of fly ash in geotechnical applications when it is environmentally safe. Fly ash is classified as either Class C or Class F ash based on its chemical composition. American Association of State Highway Transportation Officials (AASHTO) M 295 [American Society for Testing and Materials (ASTM) Specification C 618] defines the chemical composition of Class $\mathrm{C}$ and Class $\mathrm{F}$ fly ash. The properties of cement are shown in table 3.

Table 3: Chemical Properties of Fly Ash

\begin{tabular}{|c|c|c|}
\hline Compound & Typical class C fly ash & Typical class F fly ash \\
\hline $\mathrm{CaO}$ & 24.3 & 8.7 \\
\hline $\mathrm{SiO}_{2}$ & 39.9 & 54.9 \\
\hline $\mathrm{Al}_{2} \mathrm{O}_{3}$ & 16.7 & 25.8 \\
\hline $\mathrm{Fe}_{2} \mathrm{O}_{3}$ & 5.8 & 6.9 \\
\hline $\mathrm{MgO}$ & 4.6 & 1.8 \\
\hline $\mathrm{SO}_{3}$ & 3.3 & 0.6 \\
\hline $\mathrm{CaO} / \mathrm{SiO}_{2}$ & 0.61 & 0.16 \\
\hline
\end{tabular}

\section{Soil Sample Preparation and Experiments}

Cement and Fly ash mixed in varying percentage of 5\%,10\% and $15 \%$ with natural soil. The fly ash, cement \& soil has been mixed fully on dry weight basis in the suitable required proportions. There are different test sieve analysis, liquid limit, plastic limit, compaction, UCS and CBR test were performed in laboratory as per ASTM code standards. The following tests are conducted:

* Sieve analysis (ASTM D422-63)

* Liquid limits (ASTM D2487-90)

* Plastic limit (ASTM D2487-90)

- Compaction (ASTM D-698-00)

UCS (ASTM D-2166-98)

$*$ CBR (ASTM D-1883-99)

\subsection{Expansivity Measurement}

\section{Results and discussion}

By standard laboratory test as per ASTM, soil properties and expansivity (predicted) can be measured. Attergberg limit test show that the liquid limit, plastic limit and plasticity index of the soil sample collected from Barisal district are 35.8, 19.11 and 16.69. Comparing with the other research untreated sample, the following effects of liquid limit and plastic limit observed and find the soil Degree of expansion.

Table 4: Soil expansivity prediction by liquid limit

\begin{tabular}{|c|c|c|c|}
\hline Degree of Expansion & Chen[7] & IS 1498[8] & \multirow{2}{*}{ Test Result } \\
\hline Low & $<30$ & $20-35$ & \multirow{2}{*}{35.8} \\
\hline Medium & $30-40$ & $35-50$ & \\
\hline High & $40-60$ & $50-70$ & \\
\hline Very High & $>60$ & $70-90$ & \\
\hline
\end{tabular}

Table 5: Soil expansivity prediction by plasticity Index

\begin{tabular}{|c|c|c|c|c|}
\hline $\begin{array}{c}\text { Degree of } \\
\text { Expansion }\end{array}$ & Chen[7] & IS 1498[8] & Holtz and Gibbs[9] & Test Result \\
\hline Low & $0-15$ & $<12$ & $<20$ & \multirow{2}{*}{16.69} \\
\hline Medium & $10-35$ & $12-23$ & $12-34$ & \\
\hline High & $20-55$ & $23-32$ & $23-45$ & $>32$ \\
\hline Very High & $>35$ & $>32$ & & \\
\hline
\end{tabular}


The table 4 and 5 represents the soil expansivity prediction based on liquid limit and plasticity index value of the soil. These two table indicates the soil sample were medium expansive in nature.

\subsection{Unconfined Compression Test}

Table 6: Unconfined compression strength $(\mathrm{kPa})$ of soil sample with different percentage of cement

\begin{tabular}{|c|c|c|c|c|}
\hline \multirow{2}{*}{ Curing Period (days) } & \multicolumn{4}{|c|}{ Percentage of cement content (\%) } \\
\cline { 2 - 5 } & Natural Soil, 0\% & 5 & 10 & 15 \\
\hline 7 & 115.91 & 212.32 & 238.95 & 253.41 \\
\hline 14 & 124.97 & 232.81 & 306.82 & 347.19 \\
\hline 21 & 129.81 & 338.78 & 396.38 & 439.34 \\
\hline 28 & 134.26 & 398.85 & 478.76 & 546.76 \\
\hline
\end{tabular}

Table 7: Unconfined compression strength $(\mathrm{kPa})$ of soil sample with different percentage of fly ash

\begin{tabular}{|c|c|c|c|c|}
\hline \multirow{2}{*}{ Curing Period (days) } & \multicolumn{4}{|c|}{ Percentage of fly ash content (\%) } \\
\cline { 2 - 5 } & Natural Soil, 0\% & 5 & 10 & 15 \\
\hline 7 & 109.23 & 143.31 & 210.54 & 198.53 \\
\hline 14 & 113.74 & 159.34 & 233.26 & 253.51 \\
\hline 21 & 120.11 & 173.45 & 288.64 & 358.32 \\
\hline 28 & 126.24 & 217.81 & \\
\hline
\end{tabular}

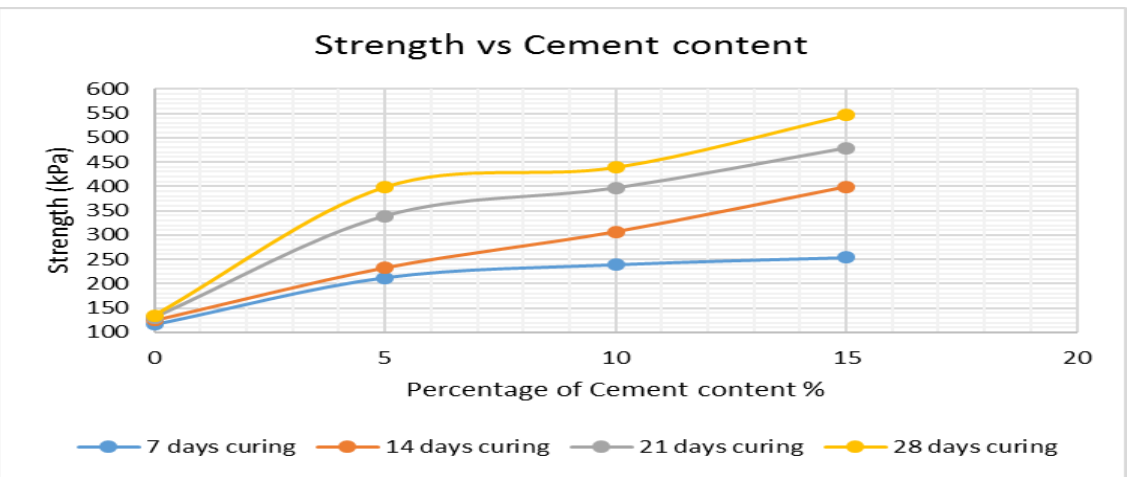

Figure 1: Strength development of soil sample for different Cement content

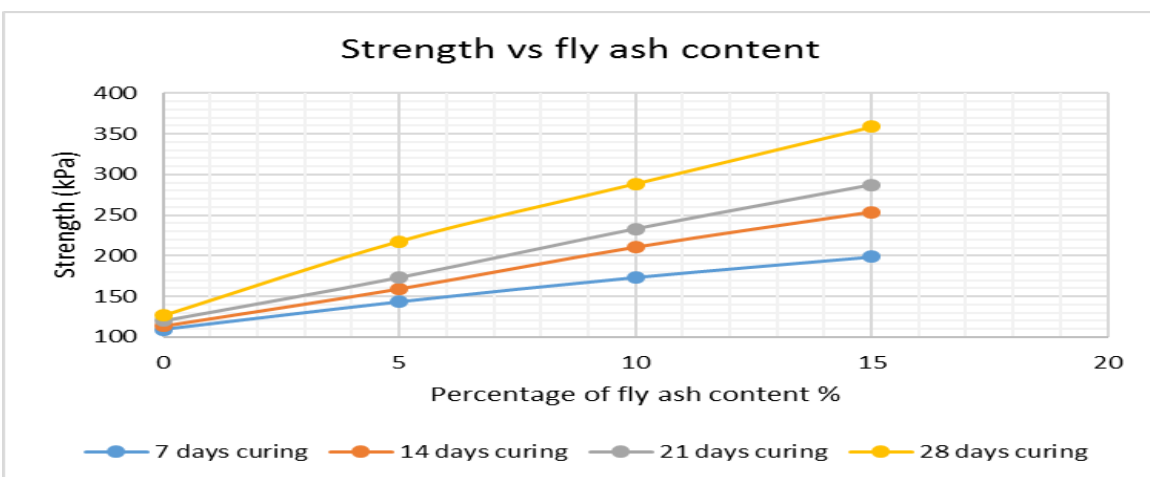

Figure 2: Strength development of soil sample for different Fly Ash content

Based on the results accessible in table 6 and 7, it observed that the strength development of soil was maximum when the percentage of cement and fly ash increased with curing period. Both cement and fly ash has a significant effect on the strength development but rapid and maximum strength gained from cement treated soil. Fly ash treated soil also shows noteworthy results. As well as, from Fig 1 and 2 can be gathered a noticeable information that is strength development with fly ash closely linear whereas strength development of cement treated soil fluctuating and naturally changed with different percentage of cement content.

\subsection{California Bearing Ratio}

Table 8: California Bearing Ratio (Soaked) value of soil sample with different percentage of Cement

\begin{tabular}{|c|c|c|c|c|}
\hline \multirow{2}{*}{ Curing Period (days) } & \multicolumn{3}{|c|}{ Percentage of cement content (\%) } \\
\cline { 2 - 5 } & Natural Soil, 0\% & 5 & 10 & 15 \\
\hline 7 & 1.73 & 2.87 & 3.73 & 4.69 \\
\hline 14 & 1.76 & 3.41 & 4.33 & 5.08 \\
\hline 21 & 1.78 & 4.59 & 5.43 & 10.76 \\
\hline 28 & 1.79 & 6.12 & 8.31 & \\
\hline
\end{tabular}


Table 9: California Bearing Ratio (Soaked) value of soil sample with different percentage of fly ash

\begin{tabular}{|c|c|c|c|c|}
\hline \multirow{2}{*}{ Curing Period (days) } & \multicolumn{4}{|c|}{ Percentage of fly ash content (\%) } \\
\cline { 2 - 5 } & Natural Soil, 0\% & 5 & 10 & 2.89 \\
\hline \\
\hline 7 & 1.84 & 2.45 & 3.17 & 3.41 \\
\hline 14 & 1.88 & 2.81 & 3.82 & 3.72 \\
\hline 21 & 1.91 & 3.23 & 4.67 & 5.57 \\
\hline 28 & 1.93 & 4.01 & 5.87 \\
\hline
\end{tabular}

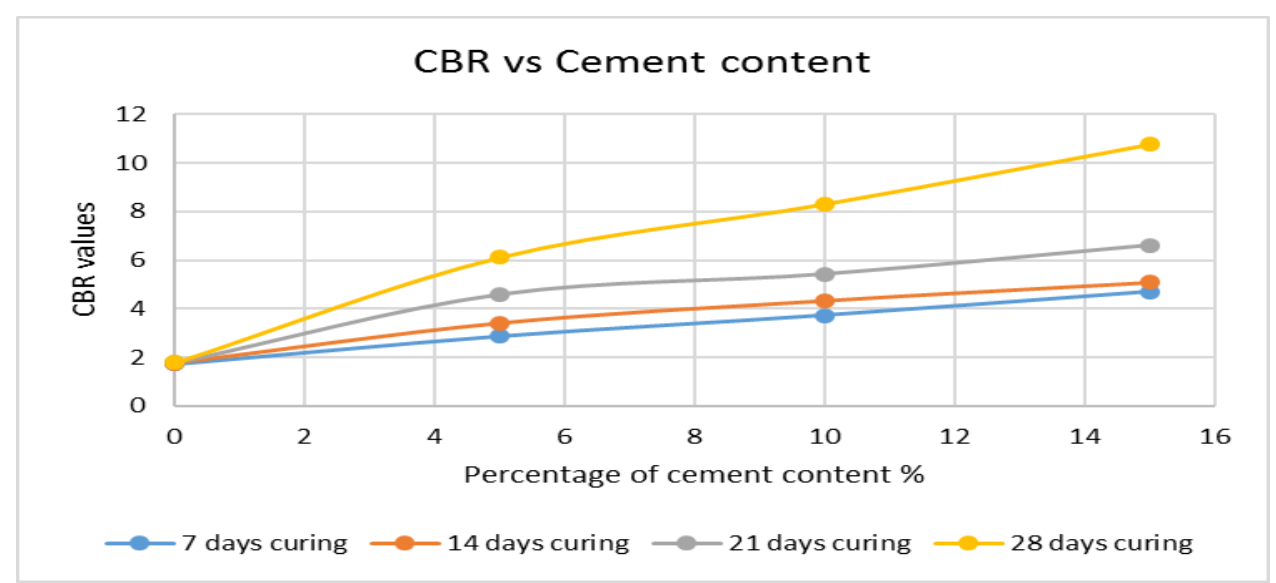

Figure 3: CBR values of soil sample for different Cement content

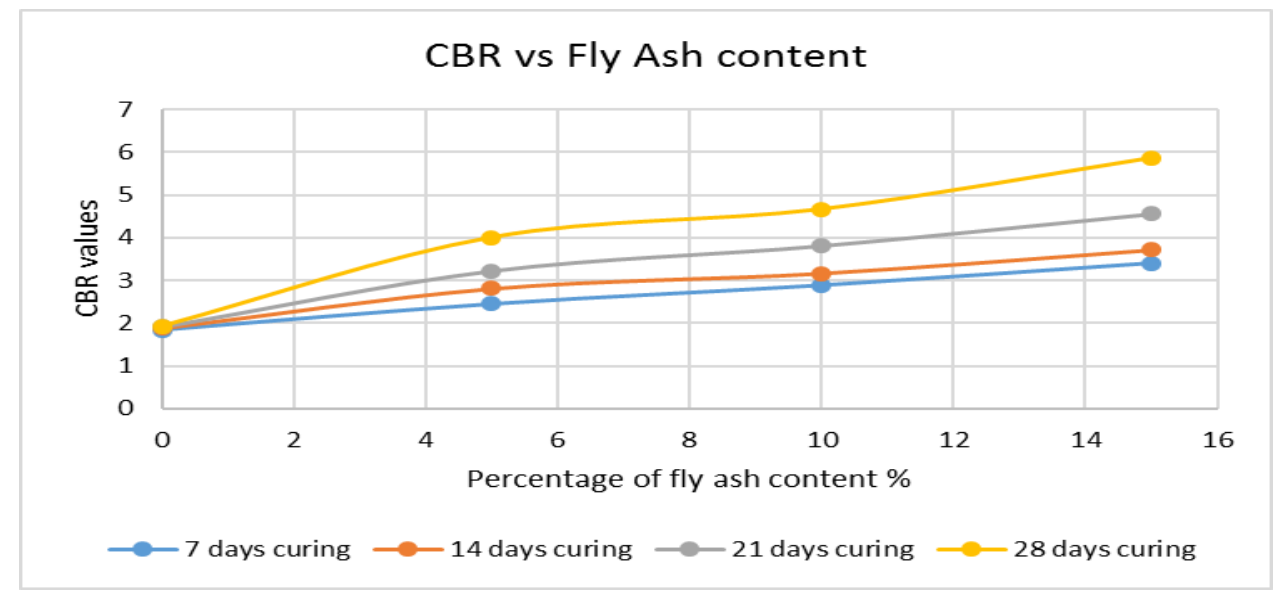

Figure 4: CBR values of soil sample for different Fly Ash content

Based on the results accessible in table 8 and 9, it observed that the CBR value of soil was maximum when the percentage of cement and fly ash increased with curing period. Both cement and fly ash has a significant effect on the CBR value but cement treated soil shows the maximum CBR value 10.76 for $15 \%$ of cement content. Fly ash treated soil also shows striking results. Furthermore, from Fig 1 and 2 gathered a clear information that is strength development with fly ash closely linear however for $15 \%$ of fly ash treated soil, fluctuating results has been detected in the Fig 2.

\section{Conclusion}

The following conclusions can be drawn from the present investigation:

1. Expansive soil can create problem during and after construction so it is must be identified before construction work. After identifying the type of expansivity, mitigation measures and suitable stabilization technique can be considered.

2. Unconfined compressive strength of cement and fly ash treated soil increased with the incremental percentage. Evaluation of effectiveness of a stabilization agent based solely on improvement of unconfined compressive strength of treated soil as done by current state of practice is not safe. Since soil, behavior is mainly controlled by confining pressure and water content performing triaxial test to simulate the field condition, in addition to unconfined compressive strength test is necessary.

3. CBR value of $\mathrm{BC}$ soil also increase with increasing varying percentages cement and fly ash. Both the optimum percentage of cement and fly ash at $15 \%$ for gave the best result for sub grade soil. 
4. Cement treated soil shows the maximum results for both UCS and CBR value. On the other hand fly ash treated soil also shows impactful results also it is considerable that fly ash is a cost effective material and has significant environmental benefits.

\section{Journal Papers:}

\section{References}

[1] Bjerrum, L., and Eide, O. (1956). Stability of strutted excavations in clay. Geotechnique 6,115-128

[2] Herrin, M. \& Mitchell, H. (1961) Lime-soil mixtures. Highway Research Board, Bulletin 304, p. 99-121.

[3] Phani Kumar S. R. and Sharma R. S. (2004). "Effect of fly ash on engineering properties of expansive soils." J. Geotech. Geoenviron. Eng., 130(7),764-767

[4] Malhotra, V. M., and Mehta, P. K. (1996). Pozzolanic and cementitious materials, Gordon and Breach, Amsterdam, Netherlands.

[5] Cokca, E. 2001. "Use of class C fly ash for the stabilization of an expansive soil." J. Geotech. Geoenviron. Eng., 127. 7. [568-573.]

[6] Åhnberg H. and Johansson S.-E., 2005. "Increase in strength with time in soils stabilised with different types of binder in relation to the type and amount of reaction products". Proceedings International Conference on Deep Mixing, Stockholm 2005, Vol. 1.1, pp. 195-202.

[7] CHEN F. H. Foundations on Expansive Soils. Elsevier, Amsterdam, 1975.

[8] BUREAU OF UREAU OF INDIAN STANDARDS. Indian Standard Classification and Identification of Soils for General Engineering Purposes. BIS, New Delhi, 1970, (Reaffirmed 1987), IS 1498.

[9] HOLTZ W. G. and GIBBS H. J. Engineering properties of expansive clays. Transactions of ASCE, 1956, 121, 641-663.

Md. Jan - E - Alam. "A Comparative Study on Stabilization of Natural Medium Expansive Soil using Cement and Fly ash ." IOSR Journal of Mechanical and Civil Engineering (IOSR-JMCE) 14.4 (2017): 30-35. 